\title{
Effect of cyclosporin A on immunological response in lungs of guinea pigs infected with Trichinella spiralis ${ }^{\star \star}$
}

\author{
Jolanta M. Dzik ${ }^{1}{ }^{凶}$ Zbigniew Zieliński $^{1}$, Barbara Gołos ${ }^{1}$, Elżbieta Jagielska ${ }^{1}$, \\ Mariusz Wranicz ${ }^{2}$ and Elżbieta Wałajtys-Rode ${ }^{3}$ \\ ${ }^{1}$ Nencki Institute of Experimental Biology, Polish Academy of Sciences, Warszawa, Poland; \\ ${ }^{2}$ Institute of Parasitology, Polish Academy of Sciences, Warszawa, Poland, and ${ }^{3}$ Institute of \\ Biology and Environmental Protection, Rzeszów University, Rzeszów, Poland
}

Received: 10 September, 2001; revised: 21 January, 2002; accepted: 27 February, 2002

Key words: Trichinella, trichinellosis, lungs, bronchoalveolar lavage, nitric oxide, superoxide, cyclosporin A

\begin{abstract}
The effects of cyclosporin A (CsA), a potent immunosuppressive drug with antiparasitic activity, on the innate immunological response in guinea pig lungs during an early period (6th and 14th days) after $T$. spiralis infection were studied. CsA treatment of $T$. spiralis-infected guinea pigs caused a significant attenuation of immunological response in lungs by decreasing lymphocyte infiltration into pulmonary alveolar space, inhibiting alveolar macrophage superoxide anion production and lowering both the production of NO metabolites measured in bronchoalveolar lavage fluid and expression of the iNOS protein in lung homogenates, allowing us to speculate that the T. spiralis-dependent immunological response is dependent on lymphocyte $T$ function. Interestingly, CsA itself had a pro-inflammatory effect, promoting leucocyte accumulation and macrophage superoxide production in guinea pig lungs. This observation may have a relevance to the situation in patients undergoing CsA therapy. Macrophage expression of the iNOS protein, evaluated by immunoblotting was not influenced by treatment of animals with CsA or anti-TGF-antibody, indicating different regulation of the guinea pig and murine enzymes.
\end{abstract}

Trichinellosis is a serious disease caused by the parasitic nematode Trichinella spiralis. It invades man and other mammals and causes pathological changes in various tissues includ-

\footnotetext{
${ }^{\star}$ Presented at the 8th International Symposium Molecular Aspects of Chemotherapy, September, 2001, Gdańsk, Poland.

Supported by the State Committee for Scientific Research (KBN, Poland) grant No. 4 P05F 02414.

${ }^{\square}$ Corresponding author: Jolanta M. Dzik, Nencki Institute of Experimental Biology, Polish Academy of Sciences, L. Pasteura 3, 02-093 Warszawa, Poland; Phone: (48 22) 6598571 ext. 369.
}

Abbreviations: BAL, bronchoalveolar lavage; BALF, bronchoalveolar lavage fluid; CsA, cyclosporin A; FBS, fetal bovine serum; HBSS, Hank's balanced salt solution; iNOS, inducible nitric oxide synthase; LPS, Escherichia coli lipopolysaccharide; hrIFN- $\gamma$, human recombinant interferon gamma. 
ing lungs (Weatherly, 1983). Mating of adult worms (developing from infective larvae) occurs in the epithelium of the host's small intestine. The fertilized females enter the intestinal wall and release newborn larvae to the bloodstream (Despommier, 1993). These, penetrating host's skeletal muscles, pass on their way the liver and lung microvascular systems (Wang \& Bell, 1986). Larval cuticular fragments, found in the lungs of $T$. spiralis-infected rats (Bruschi et al., 1992), may act as antigens stimulating both specific and nonspecific defense reactions during the so called "lung phase" of infection. Gastrointestinal nematode infections are known to be controlled by T-cell mechanisms of immunity (Miller, 1984) via the release of lymphokines, generating acute inflammatory response (Bolas-Fernandez et al., 1988). Granulocytes and macrophages have been shown in vivo to be involved in killing newborn larvae by antibody-dependent cytotoxic mechanisms (Bell, 1998).

The fungal cyclic undecapeptide cyclosporin $\mathrm{A}(\mathrm{CsA})$ is a potent immunosuppressive agent causing a specific and reversible inhibition of $\mathrm{T}$ helper lymphocyte activation and function. CsA inhibits production of cytokines (IL-2, IL-6, IFN- $\gamma$ ) by T helper lymphocytes stimulated through the $\mathrm{T}$ cell antigen receptor pathway (Colombani \& Hess, 1987; Bunjes et al., 1981). This results in an indirect inhibitory effect on growth and differentiation of B lymphocytes and other antigen-presenting cells. Indirect inhibitory effects of CsA on mastocytes, eosinophils and natural killer cells have been also described (Thomson, 1992). Numerous studies revealed macrophage functions, e.g. phagocytic activity, chemotactic migration, superoxide and peroxide production and protein secretion, to be unchanged or reduced in the presence of CsA (Losa Garcia et al., 1998; Svenson et al., 1995; reviewed by Thomson, 1992). Inhibitory effects of CsA on nitric oxide production in macrophages have also been reported (Conde et al., 1995; Hattori \& Nakanishi, 1995).
In addition to the complex immunomodulatory action, CsA was also found to exert potent anti-parasitic effects, observed during infections by both protozoan and metazoan parasites (Chappel \& Wastling, 1992). Since cyclosporin A is both antiparasitic and immunomodulatory, its clinical use in the management of organ transplantation has implications for opportunistic parasitic infections in postoperative patients (Chappel \& Wastling, 1992).

Pulmonary alveolar macrophages, together with neutrophils, form the first line of lung defence against pathogens. Nonspecific immune response involves production of reactive metabolites of oxygen and nitrogen by macrophages of many species, originating from the activities of the NADPH oxidase complex and inducible nitric oxide synthase (iNOS, EC 1.14.13.39; induced by macrophage-antigen contacts), respectively (Morel et al., 1991; Oswald et al., 1994). Regulation of iNOS expression is under control of two cytokines: IFN- $\gamma$ being activatory, and TGF- $\beta$ being inhibitory (Iyengar et al., 1987; Nathan \& Xie; 1994; Vodovotz et al., 1996). Superoxide anion and nitric oxide, as well as their metabolites, are highly toxic for most pathogens, including parasitic nematodes (James, 1995; Miller \& Britigan, 1997), but little is known about their role in the defence against $T$. spiralis infection.

Our earlier studies showed that T. spiralis infection evokes a response in the lungs of guinea-pigs during an early period (4-14 days after infection), manifested by an increase of cellular infiltration of alveolar space and transient activation of superoxide production by cultured alveolar macrophages (Dzik et al., 2000). The present study was aimed at examining the effects of $\mathrm{CsA}$ on the innate immunological response in guinea pig lungs following $T$. spiralis infection, on 6 th and 14 th days after infection, i.e. at the time of possible consequences of the passage of newborn larvae through the vascular bed of lungs (5-6th days after infection, cf. Bruschi et al., 1992) were 
expected. The influence of CsA treatment was followed on cellular infiltration into pulmonary alveolar space, production of superoxide anion and nitric oxide (the latter resulting from NOS activity) by cultured alveolar macrophages and accumulation of nitric oxide metabolites (nitrites and nitrates) in bronchoalveolar lavage fluid (BALF) and lung tissue. In addition, expression of iNOS was evaluated by immunobloting in macrophages obtained from animals infected with T. spiralis and treated with CsA or anti-TGF- $\beta$ antibody.

\section{MATERIALS AND METHODS}

Reagents. RPMI-1640, DMEM (without phenol red), Hank's balanced salt solution (HBSS), phosphate-buffered saline (PBS), fetal bovine serum (FBS), Aspergillus sp. nitrate reductase, catalase, ferricytochrome c, Escherichia coli lipopolysaccharide (LPS), anti-TGF- $\beta$ antibodies and cyclosporin A were from Sigma (St. Louis, MO, U.S.A.). $\left[{ }^{14} \mathrm{C}\right]$ Arginine was from Amersham. Monoclonal antibodies (IgG1) against iNOS were from Transduction Laboratories, and monoclonal antibodies against nitrotyrosine were from Upstate Biotechnology. Amplified OPTI-4CN kit was from Bio-Rad.

Animal treatment. Guinea pigs tricolor (250-350 g), both sexes, were purchased from a farm in Zamienie (Poland). All experimental procedures were according to the guidelines of and approved by the Animal Care Committee at the Stefański Institute of Parasitology of the Polish Academy of Sciences.

Trichinella spiralis: maintenance and infection. Parasites were maintained and infective larvae isolated as previously described (Dabrowska et al., 1996). Guinea pigs were infected per os with 4000 larvae/animal (Lindor et al., 1983) and kept under standard conditions. Bronchoalveolar lavage (BAL) was performed on 6th and 14th days after infection. Uninfected guinea pigs served as controls.
CsA treatment. The drug ( $20 \mathrm{mg} / \mathrm{kg}$ of body weight) in olive oil was given (per os) in 6 doses: 48 and $24 \mathrm{~h}$ before infection with $T$. spiralis and 24, 48, 72 and $96 \mathrm{~h}$ after infection. Animals treated only with CsA obtained placebo on the day of infection of the animals with T. spiralis. BAL was performed in all investigated groups on the 6th and 14th days after infection with $T$. spiralis larvae or introduction of placebo.

BCG treatment. In the BCG-treated group, each animal was given (i.p.) the suspension, containing $1.5 \times 10^{6}$ viable lyophilized Mycobacterium bovis bacilli (BCG vaccine from Serum and Vaccine Institute, Lublin, Poland), in a single dose and BAL was performed after 10 days.

Anti-TGF- $\beta$ antibody treatment. Polyclonal antibodies against TGF- $\beta(0.375 \mathrm{mg}$ in $0.5 \mathrm{ml}$ of $0.9 \% \mathrm{NaCl}$ ) were injected twice on the 3 th and 5 th days after $T$. spiralis infection into vena femoralis of anaesthetized guinea pigs. Paralelly, T. spiralis-infected animals, used as controls, were injected with $0.9 \% \mathrm{NaCl}$. BAL was performed on the 6th day after infection.

Bronchoalveolar lavage (BAL). Each animal was anaesthetized with sodium pentobarbital (Nembutal, $75 \mathrm{mg} / \mathrm{kg}$ body weight i.p.). After intratracheal intubation BAL was performed by introducing and aspirating PBS (three 6-ml allotments). The combined BALF was centrifuged ( $400 \times \mathbf{g}, 5 \mathrm{~min})$. The cell pellet was suspended in PBS, cell number and viability (always > 90\%) were determined, smears were prepared and the remaining material was taken for macrophage isolation. Differential cell counts were performed (under a light microscope) after staining of smears with May-Grünwald-Giemsa stain (with 500 cells counted).

Lung samples. Following BAL, lungs were perfused with PBS, dissected and homogenized (in an ice bath) with $0.15 \mathrm{M} \mathrm{KCl}$ containing $1 \mathrm{mM}$ phenylmethylsulfonyl fluoride (PMSF) and $1 \mu \mathrm{g} / \mathrm{ml}$ leupeptin. Homogenates were centrifuged at $20000 \times \boldsymbol{g}$ for $20 \mathrm{~min}$ at $4^{\circ} \mathrm{C}$. 
Isolation and cultivation of alveolar macrophages. BALF cells were plated (2-4 $\times 10^{6}$ cells per dish) in HBSS and alveolar macrophages isolated by the selective adherence to Petri dish. After $2 \mathrm{~h}$ incubation $\left(37^{\circ} \mathrm{C}\right.$, $5 \% \mathrm{CO}_{2}$ ) HBSS medium was changed for RPMI-1640 or DMEM (without phenol red) containing 10\% FBS and the adherent macrophages (always $>85 \%$ pure and $>95 \%$ viable) were incubated for $18 \mathrm{~h}$ with or without additions as indicated.

Superoxide anion $\left(\mathrm{O}_{2}^{-}\right)$formation. Assays were performed in macrophages washed twice with $0.9 \% \mathrm{NaCl}$. Production of $\mathrm{O}_{2}^{-}$was determined based on superoxide dismutase-inhibited reduction of ferricytochrome $c$ (Yamashita et al., 1985). Briefly, following incubation of macrophages in HBSS containing $80 \mu \mathrm{M}$ ferricytochrome $c$ and $20 \mu \mathrm{g} / \mathrm{ml}$ catalase, with or without superoxide dismutase $(20 \mu \mathrm{g} / \mathrm{ml})$, samples were withdrawn at $0,15,30,45$ and $60 \mathrm{~min}$ and absorbance was measured at $550 \mathrm{~nm}\left(\varepsilon=21000 \mathrm{M}^{-1}\right.$ $\mathrm{cm}^{-1}$ ).

Cell lysates. Cultured macrophages were placed on ice and lysed with $200 \mu \mathrm{l}$ of ice-cold lysis buffer containing $50 \mathrm{mM}$ Tris-buffered saline, $\mathrm{pH} 8,10 \%$ glycerol, $1 \%$ Triton X-100, 5 $\mathrm{mM}$ PMSF, leupeptin and pepstatin (each $2 \mu \mathrm{g} / \mathrm{ml}$ ), and $1 \mathrm{mM}$ dithiothreitol (DTT). Lysates were centrifuged $\left(9000 \times \mathbf{g}, 4^{\circ} \mathrm{C}, 5\right.$ min) and supernatants stored at $-20^{\circ} \mathrm{C}$ until assayed for NOS activity and protein expression.

Nitric oxide synthase activity. The assay was based on $\left[{ }^{14} \mathrm{C}\right]$ citrulline production from $\left[{ }^{14} \mathrm{C}\right]$ arginine (Xia \& Bredt, 1998). Briefly, cell lysates $(25 \mu \mathrm{l})$ were added to a reaction mixture containing $25 \mathrm{mM}$ Tris/ $\mathrm{HCl}, \mathrm{pH} 7.5$, $100 \mu \mathrm{M}\left[{ }^{14} \mathrm{C}\right]$ arginine, $3 \mu \mathrm{M}$ tetrahydrobiopterin, $1 \mu \mathrm{M}$ FAD, $1 \mu \mathrm{M}$ FMN and $1 \mathrm{mM}$ NADPH. Nonenzymatic controls were run either in the absence of NADPH or in the presence of $1 \mathrm{mM} \mathrm{N} \omega$-nitro-L-arginine methyl ester (L-NAME) in the reaction mixture. The reaction was terminated after 15 min incubation at $37^{\circ} \mathrm{C}$ by addition of $4 \mathrm{ml}$ of Hepes, $\mathrm{pH}$
5.5, containing $5 \mathrm{mM}$ EDTA. The resulting solution was applied into $0.6 \mathrm{ml}$ bed volume of Dowex $50 \times 8-400 \mathrm{Na}^{+}$form and followed by additional $4 \mathrm{ml}$ of the Hepes/EDTA buffer. The flow-through was collected in a $20 \mathrm{ml}$ scintillation vial containing $16 \mathrm{ml}$ of Bio Care scintillation cocktail and its radioactivity was measured.

Nitrite $\left(\mathrm{NO}_{2}^{-}\right)$and nitrate $\left(\mathrm{NO}_{3}^{-}\right)$measurements. $\mathrm{NO}_{2}^{-}$was measured in BALF supernatants or lung homogenates after reduction to $\mathrm{NO}_{2}^{-}$by nitrate reductase (from Aspergillus sp.) in the presence of NADPH. Excess of $\mathrm{NADPH}$ was removed by addition of lactate dehydrogenase and pyruvate (Gilliam et al., 1993). Parallely, the recovery of sodium nitrate standard was evaluated. $\mathrm{NO}_{2}^{-}$was assayed with Griess reagent (Green et al., 1982). Briefly, $100 \mu \mathrm{l}$ sample was deproteinized with $30 \mu \mathrm{l}$ of $0.5 \mathrm{M} \mathrm{NaOH}$ and $20 \mu \mathrm{l}$ of $0.4 \mathrm{M}$ $\mathrm{ZnSO}_{4}$, and centrifuged. After addition of Griess reagent ( $1 \%$ sulfanilamide in $2.5 \%$ phosphoric acid and $0.1 \%$ naphtylethylenediamide-HCl), followed by 10 min incubation, absorbance was recorded at $545 \mathrm{~nm}$. Concentrations were determined based on a standard curve prepared with sodium nitrite (0.2-5.0 $\mathrm{nmol} / \mathrm{sample}$ ). The sensitivity of the assay was $0.5 \mu \mathrm{M}$.

Immunoblot analysis. Cell lysates or lung homogenates ( $30 \mu \mathrm{g}$ of protein per lane) were subjected to SDS/polyacrylamide (10\%) gel electrophoresis and proteins were electrotransferred to PVDV membrane in a buffer containing $25 \mathrm{mM}$ Tris, $192 \mathrm{mM}$ glycine, $\mathrm{pH}$ 8.3, $20 \%$ methanol and $0.05 \%$ SDS. The enzyme protein was visualized using mouse monoclonal antibody (specific for iNOS of mouse, rat, human and dog) from Transduction Laboratories (U.S.A.). Immunodetection was performed using Amplified OPTI-4CN Kit (Bio-Rad) according to the manufacturer's protocol. As a positive control lysates from peritoneal macrophages of mice treated with BCG were used.

Protein assay. Protein concentration was measured in macrophage lysates with Cooma- 
ssie Brilliant Blue G-250 as described by Spector (1978).

Statistics. Results are presented as mean \pm S.E.M., with the number of experiments (N) given in parentheses. The nonparametric signed rank Mann-Whitney $U$ test (Siegel, 1956) was used to evaluate significance of differences (considered significant when $H_{0}$ could be rejected at $\alpha>0.05$ ) between samples.

\section{RESULTS}

\section{Cellular infiltration of alveolar space}

Consistent with our previous results (Dzik et al., 2000), guinea pig infection by T. spiralis larvae was followed by a marked increase of cell infiltration to the pulmonary alveolar space starting on the 4 th day and persisting until 14th day after infection. Macrophages, neutrophils, and eosinophils were significantly accumulated on the 6th and 14th days after infection (Fig. 1) but only an apparently transient increase of lymphocyte number on the 6th day was noted. Treatment of uninfected animals with CsA 2 days before and 4 days after placebo administration resulted in an unexpected extensive accumulation of macrophages, lymphocytes and eosinophils (reflected also by total cell number) in pulmonary alveolar space (Fig. 1A, C, D and E). Treatment of T. spiralis-infected animals with CsA resulted in significantly changed macrophage and lymphocyte infiltration observed 6 days after infection. CsA caused a further increase of total leucocyte and macrophage number with a simultaneous diminution of lymphocyte infiltration (Fig. 1A, C and E), and no change in the number of eosinophils and neutrophils (Fig. $1 \mathrm{~B}$ and D) compared with infected, non-treated animals. It should be noted that on the 14th day after infection no effect of CsA on cellular infiltration into alveolar space of infected animals was observed (Fig. 1).

\section{Superoxide anion production}

Alveolar macrophages, recovered from BALF on 6th day after infection, showed a prominent $\mathrm{O}_{2}^{-}$production, about 3-fold higher than control values (Table 1) but the difference became insignificant on the 14th day after infection. While CsA treatment doubled superoxide anion production by infiltrating macrophages of uninfected animals, it abolished the stimulation of $\mathrm{O}_{2}^{-}$production on the 6 th day and, to a lesser extent, on the 14th day after infection with $T$. spiralis (Table 1).

\section{Nitric oxide production resulting from NOS activity}

NO synthesis was not stimulated over its basic rate in alveolar macrophages from $T$. spiralis-infected animals on the 6th day after infection. Moreover, on the 14th day after infection NO production was even significantly lowered (Table 1). CsA treatment of both control and T. spiralis-infected guinea pigs was without any significant effect on NOS activity in lysates of alveolar macrophages, with the exception of the 14th day after infection, when it appeared to prevent the above mentioned lowering of NO production (Table 1). Treatment of guinea pigs in vivo with BCG vaccine, a well recognized stimulus of iNOS expression in rodents, did not increase nitric oxide production (not shown).

\section{Expression of iNOS protein in macrophages and lungs}

Immunoblot analysis of macrophage lysates from uninfected, T. spiralis-infected, and BCG-treated guinea pigs, probed with antiiNOS antibody (crossreacting with mouse, rat, dog and human iNOS), demonstrated an immunoreactive protein band (Fig. 2 ). The reactive protein is located at the position corresponding to that in the positive control (lysates from peritoneal macrophages of mouse stimulated with BCG) and is located at the same position as the prestained molecular 
mass standard of $132 \mathrm{kDa}$ (Bio-Rad). Lysate of peritoneal macrophages from non-stimulated mouse, used as a negative control, did not show the iNOS band. Cyclosporin A did not af-
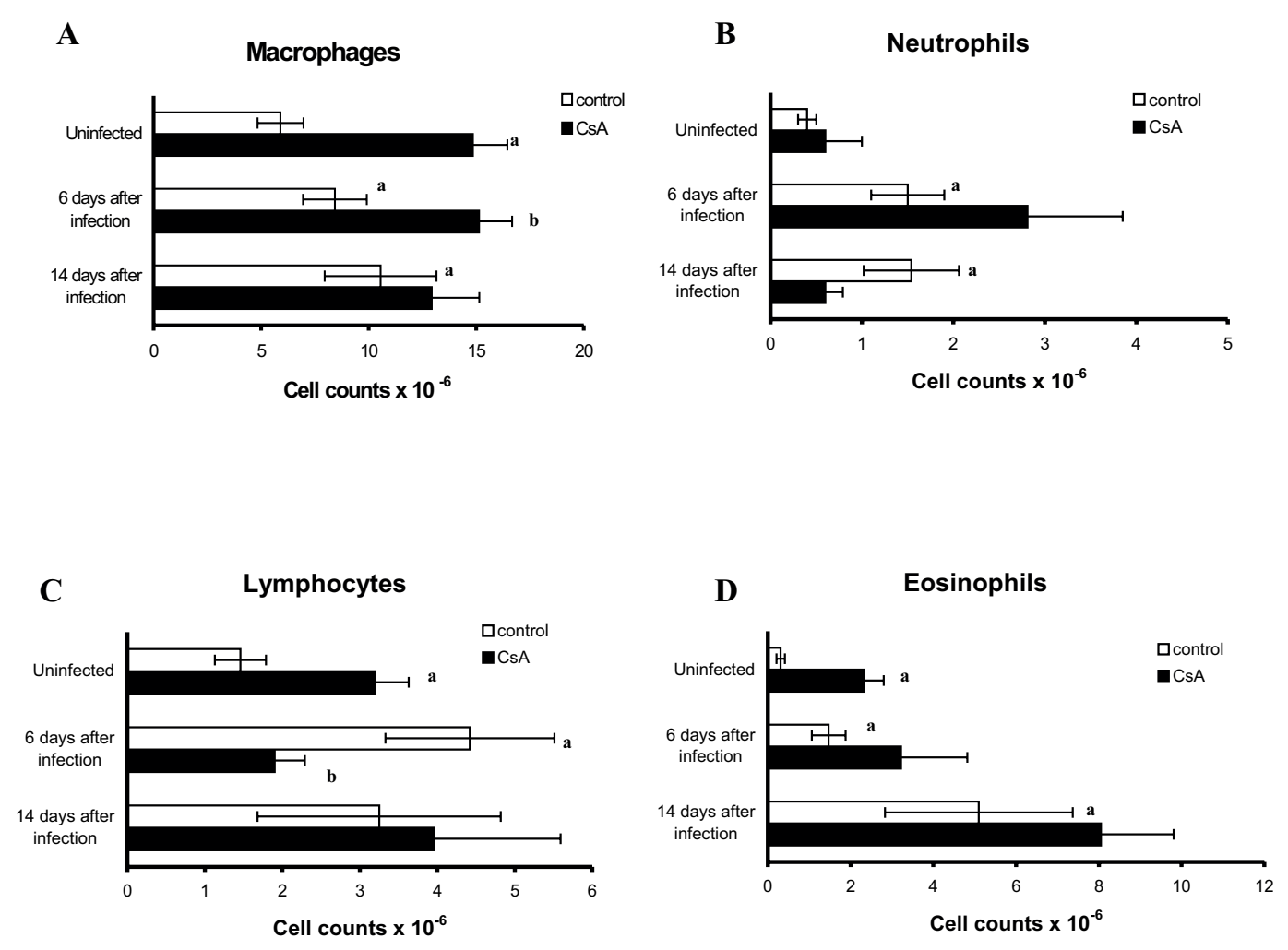

E

Total leucocytes

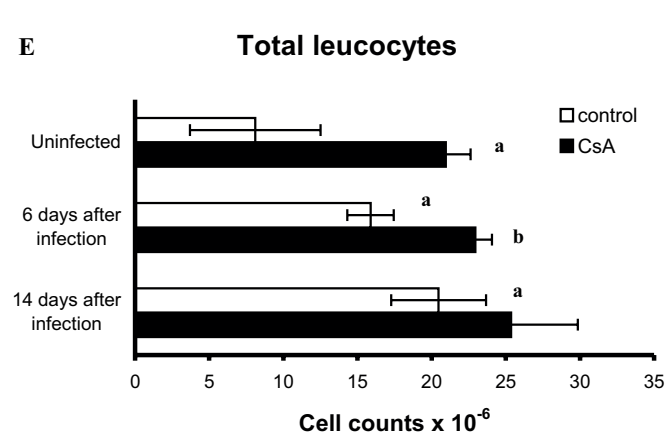

Immunoblot analysis of lung homogenates also demonstrated the presence of nitric oxide synthase in lungs of both uninfected and $T$. spiralis-infected guinea pigs (Fig. 3). In con-

Figure 1. Effect of CsA treatment on cellular infiltration of lung bronchoalveolar spaces of Trichinella spiralis-infected guinea pig.

Differential cell counts of macrophages (A), neutrophils (B), lymphocytes (C), eosinophils (D) and total leucocytes (E) recovered from BAL peformed in uninfected and T. spiralis-infected (6 and 14 days after infection) animals, ei-

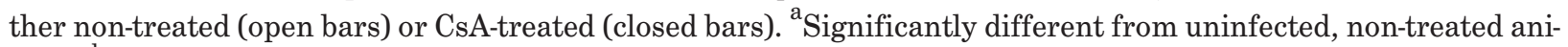
mals. ${ }^{\mathrm{b}}$ Significantly different from infected, non-treated animals.

fect expression of iNOS in macrophages both of uninfected and T. spiralis-infected guinea pigs. Also injection of antibodies against TGF- $\beta$ was without effect on iNOS expression. trast to macrophages, CsA treatment of either infected or uninfected animals suppressed expression of iNOS in the lungs. Treatment of $T$. spiralis-infected guinea pigs with anti-TGF- $\beta$ 
Table 1. Effect of cyclosporin A on superoxide anion and nitric oxide production in cultured alveolar macrophages from Trichinella spiralis-infected guinea pigs

\begin{tabular}{|c|c|c|c|c|}
\hline \multirow[t]{2}{*}{ Days after infection } & \multicolumn{2}{|c|}{$\begin{array}{c}\mathrm{O}_{2}^{-} \text {production } \\
(\mathrm{nmol} / \mathrm{mg} \text { protein per } \mathrm{h})\end{array}$} & \multicolumn{2}{|c|}{$\begin{array}{c}\text { NOS activity } \\
(\mathrm{nmol} / \mathrm{mg} \text { protein per } \mathrm{h})\end{array}$} \\
\hline & Non-treated & CsA-treated & Non-treated & CsA-treated \\
\hline Uninfected & $17.3 \pm 3.2(8)$ & $34.9 \pm 1.9(5)^{\mathrm{a}}$ & $0.7 \pm 0.2(6)$ & $1.3 \pm 0.8(4)$ \\
\hline 6 & $62.4 \pm 12.6(9)^{\mathrm{a}}$ & $30.8 \pm 2.6(5)^{b}$ & $1.7 \pm 0.5(9)$ & $0.9 \pm 0.2(3)$ \\
\hline 14 & $36.0 \pm 12.4(3)$ & $24.8 \pm 3.1(4)$ & $0.2 \pm 0.0(6)^{\mathrm{a}}$ & $1.7 \pm 0.6(5)^{b}$ \\
\hline
\end{tabular}

${ }^{\mathrm{a}}$ Significantly different $(P \leq 0.05)$ from uninfected, non-treated animals. ${ }^{\mathrm{b}}$ Significantly different $(P \leq 0.05)$ from infected, non-treated animals.

antibodies increased (2-3-fold, as indicated by densitometric estimation; not shown) the expression of iNOS in the lungs.

\section{Influence of CsA on concentration of NO metabolites in BALF and lung homogenates}

Concentration of $\mathrm{NO}$ metabolites $\left(\mathrm{NO}_{2}^{-}+\right.$ $\mathrm{NO}_{3}^{-}$) in BALF supernatant, but not in lung homogenates, of $T$. spiralis-infected guinea pigs was significantly increased on the 6th day after infection. CsA treatment resulted in a significant diminution of nitrites and nitrates concentration in BALF supernatant from T. spiralis-infected animals. The presence of anti-TGF- $\beta$ antibodies in the blood of T. spiralis-infected animals did not increase significantly the level of NO metabolites. Neither CsA nor anti-TGF- $\beta$ antibodies affected

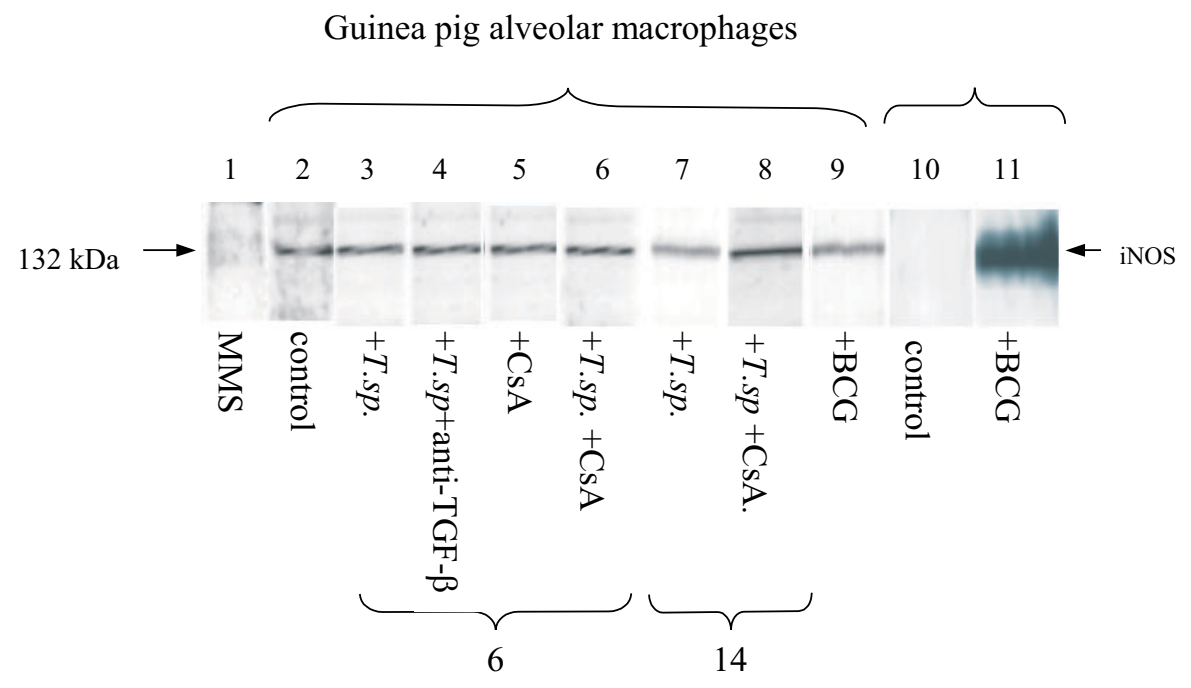

Days after T. spiralis infection

Figure 2. Expression of iNOS protein in guinea pig and mouse macrophage lysates.

Lane 1, molecular mass standards; lane 2, alveolar macrophages from uninfected, non-treated guinea pig; lane 3, alveolar macrophages isolated 6 days after T. spiralis infection of guinea pig; lane 4, alveolar macrophages isolated 6 days after T. spiralis infection and anti-TGF- $\beta$ antibody treatment (on the 3 th and 5 th days after infection) of guinea pig; lane 5, alveolar macrophages from uninfected, CsA-treated guinea pig; lane 6, alveolar macrophages isolated 6 days after T. spiralis infection and CsA treatment of guinea pig; lane 7, alveolar macrophages isolated 14 days after T. spiralis infection of guinea-pig; lane 8, alveolar macrophages isolated 14 days after T. spiralis infection and CsA treatment of guinea pig; lane 9, alveolar macrophages from BCG-treated guinea pig; lane 10, peritoneal macrophages from control mouse; lane 11, peritoneal macrophages from BCG-treated mouse. 


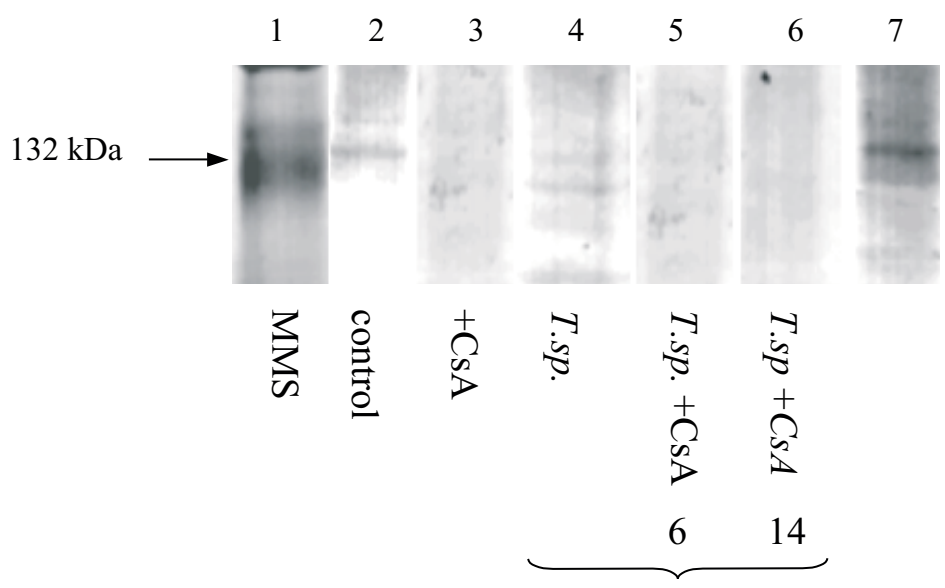

Days after T. spiralis infection

Figure 3. Expression of iNOS protein in guinea pig lungs.

Lane 1, molecular mass standards; lane 2, non-treated guinea pig lung homogenate; lane 3, CsA-treated guinea pig lung homogenate; lane 4, T. spiralis-infected guinea pig lung homogenate; lanes 5 and 6, CsA-treated and T. spiralis-infected guinea pig lung homogenate, prepared 6 and 14 days after infection, respectively; lane 7 , T. spiralis-infected and anti-TGF- $\beta$-treated guinea pig lung homogenate.

the nitrite and nitrate levels in lungs of both infected and uninfected guinea pigs (Table 2).

\section{DISCUSSION}

In the earlier studies a significant increase of cellular infiltration into pulmonary alveolar space in the early period (4-14 days) after $T$. spiralis infection, suggested that bronchoalveolar leucocytes play a significant role in lung resistance against migrating larvae (Dzik et al., 2000). Similar results were obtained by Egwang et al. (1984) who studied cellular responses in rat lungs following primary and secondary infection with Nippostrogylus brasiliensis, another parasite whose larvae migrate via blood and lymphatics through the lungs.

Table 2. Effect of cyclosporin A on $\left(\mathrm{NO}_{2}^{-}+\mathrm{NO}_{3}^{-}\right)$concentration in bronchoalveolar lavage fluids (BALF) and lung homogenates of guinea pigs infected with $T$. spiralis

\begin{tabular}{|c|c|c|}
\hline \multirow{3}{*}{ Treatment } & \multicolumn{2}{|c|}{$\left(\mathrm{NO}_{2}^{-}+\mathrm{NO}_{3}^{-}\right)$} \\
\hline & BALF supernatants & Lung homogenates \\
\hline & $(\mu \mathrm{M})$ & (nmol/g wet weight) \\
\hline \multicolumn{3}{|c|}{ Uninfected animals } \\
\hline None & $1.9 \pm 0.4(3)$ & $62.8 \pm 3.1(3)$ \\
\hline $\mathrm{CsA}$ & $2.4 \pm 0.1(5)$ & $67.1 \pm 2.1(4)$ \\
\hline \multicolumn{3}{|c|}{ Infected animals (6th day after infection) } \\
\hline None & $3.9 \pm 0.6(3)^{\mathrm{a}}$ & $78.0 \pm 4.2(3)$ \\
\hline $\mathrm{CsA}$ & $2.2 \pm 0.1(5)^{b}$ & $58.3 \pm 3.6(4)$ \\
\hline Anti-TGF- $\beta$ & $3.1 \pm 0.3(4)$ & $62.2 \pm 6.3(5)$ \\
\hline
\end{tabular}

${ }^{\mathrm{a}}$ Significanly different $(P \leq 0.05)$ from uninfected, non-treated animals. ${ }^{\mathrm{b}}$ Significanly different $(P \leq 0.05)$ from infected, non-treated guinea pigs. 
As shown in the present paper, treatment with CsA by itself significantly increased macrophage, lymphocyte and eosinophil infiltration into alveolar space of uninfected animals (Fig. 1). Many studies reveal that CsA may sometimes paradoxically enhance immune responses and induce specific forms of autoimmunity, depending on the dose, timing of drug delivery and experimental model (for a review see Prud'homme and Vanier, 1993). To our knowledge there are no data concerning the effects of $\mathrm{CsA}$ on cellular infiltration in the lungs. In other tissues increased accumulation of macrophages and granulocytes after CsA treatment has been reported (Dick et al., 1997; Taskinen \& Roytta, 2000). Most studies were dealing with the effects of CsA on the antigen-induced immunological response, expressed mainly by eosinophil infiltration, induced in the lungs in vivo or in vitro.

Treatment with oral CsA affected the response of guinea pigs to the parasite by markedly increasing $T$. spiralis-induced total cell accumulation in alveolar space on the 6th day after infection (Fig. 1E). Polymorphonuclear leucocyte infiltration in CsA-treated, T. spiralis-infected guinea pigs, was increased non-significantly due to high individual variations (Fig. 1B, D). Similarly, Ceyhan et al. (1998) observed increased total number of BAL cells after inhalation of CsA by ovalbumin-sensitized rats.

Apart from a beneficial effect of CsA on allergen-induced bronchial eosinophilia in guinea pigs in vivo (Lagente et al., 1994), no significant effect on BALF eosinophil content was found during hypersensitivity pneumonitis caused by actinomycete Faeni rectivirgula in mice (Denis et al., 1992) or acute cutaneous inflammation in guinea pigs (Teixeira et al., 1996). According to Norris et al. (1992), CsA treatment following sensitization did not reduce antigen-induced eosinophilia in guinea pig lungs but abolished it when the drug was given at the time of sensitization. A pro-inflammatory action of CsA was described also by Wang et al. (1993), who observed in- creased eosinophil recruitment in the lungs of mice with allergic bronchopulmonary aspergillosis after pretreatment with the drug.

It has to be pointed out that while CsA maintained significantly increased macrophage accumulation, it prevented lymphocyte infiltration induced by $T$. spiralis on the 6th day after infection (Fig. 1A and C). Decreased lymphocyte infiltration was also described in BALF of mice with hypersensitivity pneumonitis caused by $F$. rectivirgula in vivo (Denis et al., 1992) and in sensitized rats with allergen induced hyperresponsiveness (Elwood et al., 1992). A decrease lymphocyte accumulation by CsA has been proposed to be due to the drug's ability to suppress lymphokine production and inhibit of leucocyte-endothelial interactions (Issekutz, 1989; De Caterina et al., 1995; Chapman \& Mazzoni, 1994). The lack of CsA effect on cellular infiltration of bronchoalveolar space induced by $T$. spiralis on 14 th day after infection may be due to the limited availability of the drug at this time interval (Kahan, 1994).

While the ability of CsA to induce reactive metabolites of oxygen has been extensively studied, its mechanism is still unclear. It has been shown that CsA toxicity in kidney, liver and nervous system is accompanied by increased both $\mathrm{H}_{2} \mathrm{O}_{2}$ production and lipid peroxidation, and concominantly decreased cellular level of reduced glutathione (Suleymanlar et al., 1994; Wolf et al., 1994; Calo et al., 2000). Stimulation of superoxide production and significant prolongation of ADP-stimulated superoxide production have been observed in rat alveolar macrophages treated with CsA in vitro (Forman et al., 1998). In accord, alveolar macrophages of uninfected guinea pigs responded to treatment of animals with CsA by stimulation of superoxide anion production (Table 1). In unstimulated cells CsA may influence the dephosphorylation processes accompanying activation of NADPH oxidase, as okadaic acid, a protein phosphatase $2 \mathrm{~A}$ inhibitor, has been shown to prolong the oxidase activation caused by 
phorbol ester or formyl-methionyl-leucyl-phenylalanine in human neutrophils ( $\mathrm{Lu}$ et al., 1992).

CsA treatment caused an attenuation of the enhanced $\mathrm{O}_{2}^{-}$production by macrophages from T. spiralis-infected animals (Table 1), suggesting the signal for activation of macrophage NADPH oxidase to be inhibited by CsA. A similar inhibitory effect of CsA was observed by Chiara et al. (1989) in phorbol ester-stimulated resident peritoneal mouse macrophages. With respect to the latter, it has been shown that CsA inhibits cytokine gene expression in activated $\mathrm{T}$ lymphocytes and macrophages (Thomson, 1992; Svensson et al., 1995) by blocking calcineurin, a $\mathrm{Ca}^{2+}$ /calmodulin dependent serine/threonine phosphatase (Liu et al., 1991).

NOS activity in cultured guinea pig alveolar macrophages was not increased on the 6th and decreased on 14th day after T. spiralis infection. Following CsA treatment, the activity was unchanged on 6 th and 14 th days after infection, but on 14th day after infection it was higher than in non-treated control (Table 1). Hence, CsA treatment appears to prevent the lowering of NOS activity, observed on 14th day after $T$. spiralis infection. It is well established that expression and activity of iNOS in rodent macrophages is induced by LPS, IFN- $\gamma$, TNF- $\alpha$ or BCG (Morris \& Billiar, 1994; Zhang \& McMurray, 1998), although species differences have been reported (Salter et al. 1991; Jesch et al., 1997). Guinea-pig alveolar macrophages did not produce $\mathrm{NO}$ after in vitro stimulation with hrIFN- $\gamma$ and/or LPS or BCG (Zhang \& McMurray, 1998). Comparative studies revealed that Legionella pneumophilia infection caused induction of NO production in mouse, but not in guinea pig, peritoneal macrophages (Rajagopalan-Levassieur et al., 1996). However, endothelial and/or epithelial cells of airways (Rochelle et al., 1998; Nijkamp et al., 1993) are a potential source of NO metabolites recovered in BALF supernatant and might be responsible for the observed increase of nitrate and nitrite accumulation (Ta- ble 2). Since endothelial cells are in intimate contact with larvae during their intravascular lung migration phase, it is tempting to speculate that they may play role in a defense mechanisms in vivo (cf. Oswald et al., 1994). However, this effect was attenuated by CsA treatment, although CsA did not effect NO metabolite production in uninfected animals (Table 2), which argues against the involvement of endothelial NOS known to be stimulated by CsA treatment (Navarro- Antolin et al., 2000).

Immunoblot analysis with a specific antiiNOS monoclonal antibody, of alveolar macrophage lysates from control and T. spiralis-infected guinea pigs, showed the presence of an immunoreactive protein, identified additionally as iNOS by its molecular mass and colocalization with a positive control (BCG-stimulated mouse peritoneal macrophages) (Fig. 2). Guinea pig macrophage iNOS expression was not influenced by in vivo treatment with CsA or anti-TGF- $\beta$ antibody (Fig. 2). In contrast, CsA has been demonstrated to inhibit iNOS expression in many cell lines, including rat aortic smooth muscle cells (Muramo et al., 1995), transformed macrophage cell line J774 (Burkart et al., 1992), rat renal mesangial cells (Kunz et al., 1995) and murine macrophage cell line RAW 264.7 (Attur et al., 2000). Moreover, TGF- $\beta$ is known to destabilize iNOS mRNA and decrease its translation in inflammatory mouse macrophages, as well as to reduce the level of the iNOS protein in mouse peritoneal macrophages (Vodovotz, 1997). So, neutralization of this cytokine with antibodies was expected to augment the expression of iNOS in macrophages, which was not the case. Similarly, treatment with anti-TGF- $\beta 1$ did not raise the low NO production of human monocytes in response to cytokines (Weinberg et al., 1995). The lack of influence of CsA or anti-TGF- $\beta$ antibody on iNOS expression in alveolar macrophages, isolated from both uninfected and T. spiralis-infected guinea pigs, suggests that iNOS is constitutively present in guinea pig macrophages and is regulated by 
mechanisms different from those found so far in other rodent's macrophages.

As it was mentioned above, lungs contains NOS derived from endothelial and/or epithelial cells of airways and from interstitial macrophages. The latter may explain the pattern of the iNOS expression in guinea pig lung homogenates being different from that in alveolar macrophages (Fig. 3). The available data indicate NOS isolated from guinea pig lung to be distinct from the common iNOS isoform, as it is calcium-dependent and insensitive to in vivo treatment of the animals with LPS (Salter et al., 1991; Shirato et al., 1998). Expression of iNOS in lungs of control and $T$. spiralis-infected guinea pigs was abolished by CsA treatment, but present, and even enhanced, in homogenates from T. spiralis-infected and anti-TGF- $\beta$ treated animals (Fig. 3). The sensitivity of guinea pig lung iNOS expression to CsA observed in our studies may suggest a requirement for calcineurin-mediated $\mathrm{NF} \kappa \mathrm{B}$ activation (Nathan \& Xie, 1994). Recently, Bian et al. (2001) described the iNOS protein to be expressed in control, uninfected mouse lung, the expression being lowered by T. spiralis infection. Expression of iNOS was observed also in lung (and alveolar macrophages, see above) of uninfected guinea pigs but it was not lowered by the infection (Figs. $2,3)$.

The present results indicate that iNOS expression in guinea pig lungs is not correlated with NO metabolite production (Table 2, Fig. 3), as the effects of CsA (abolishment) and anti-TGF- $\beta$ antibodies (enhancement) on iNOS expression did not influence NO metabolite production accordingly (by either canceling or increasing this production). The latter points to the participation of other NOS isoforms.

In conclusion, it is shown that CsA by itself has a pro-inflammatory effect, promoting leucocyte accumulation and macrophage superoxide production in the lungs of guinea pigs, which may have a relevance to the situation in patients undergoing CsA therapy. However,
CsA treatment significantly attenuates the parasite-induced response in the lungs of guinea pigs, allowing one to speculate that $T$. spiralis-dependent immunological response is dependent on lymphocyte $\mathrm{T}$ function.

\section{R E F E R E N C E S}

Attur, M.G., Patel, R., Thakker, G., Vyas, P., Levartovsky, D., Patel, P., Naqvi, S., Raza, R., Patel, K., Abramson, D., Bruno, G., Abramson, S.B. \& Amin, A.R. (2000) Differential anti-inflammatory effects of immunosuppressive drugs: Cyclosporin, rapamycin and FK-506 on inducible nitric oxide synthase, nitric oxide, cyclooxygenase-2 and PGE2 production. Inflamm. Res. 49, 20-26.

Bell, R.G. (1998) The generation and expression of immunity to Trichinella spiralis in laboratory rodents. Adv. Parasitol. 41, 150-217.

Bian, K.A., Harari, Y., Zhong, M., Lai, M., Castro, G., Weibrodt, N. \& Murad, F. (2001) Down-regulation of inducible nitric oxide synthase (NOS-2) during parasite-induced gut inflammation: A path to identify a selective NOS-2 inhibitor. Mol. Pharmacol. 59, 939-947.

Bolas-Fernandez, F., Grencis, R.K. \& Wakelin, D. (1988) Cyclosporin A and Trichinella spiralis: Anthelminthic effects in immunosuppressed mice. Parasite. Immunol. 10, 111-116.

Bruschi, F., Solfanelli, S. \& Binaghi, R.A. (1992) Trichinella spiralis: Modifications of the cuticle of the newborn larvae during passage through the lung. Exp. Parasitol. 75, 1-9.

Bunjes, D., Hardt, C., Rollinghoff, M. \& Wagner, H. (1981) Cyclosporin A mediates immunosuppression of primary cytotoxic $\mathrm{T}$ cell responses by impairing the release of interleukin 1 and interleukin 2. Eur. J. Immunol. 11, 657-661.

Burkart, V., Imai, Y., Kallmann, B. \& Kolb, H. (1992) Cyclosporin A protects pancreatic islet cells from nitric oxide dependent macrophage cytotoxicity. FEBS Lett. 313, 56-58. 
Calo, L., Semplicini, A., Davis, P.A., Bonvicini, P., Cantaro, S., Rigotti, P., D’Angelo, A., Livi, U. \& Antonello, A. (2000) Cyclosporin-induced endothelial dysfunction and hypertension: Are nitric oxide system abnormality and oxidative stress involved? Transpl. Int. 13 (Suppl. 1), S413-S418.

Ceyhan, B.B., Sungur, M., Celikel, C.A. \& Celikel, T. (1998) Effect of inhaled cyclosporin on the rat airway: Histologic and bronchoalveolar lavage assessment. Respiration 65, 71-78.

Chapman, I. \& Mazzoni, L. (1994) Mechanisms of inhibition by cyclosporin A on pulmonary leukocyte accumulation. Trends Parasitol. Sci. 124, 43-48.

Chappel, L. \& Wastling, J.M. (1992) Cyclosporin A: Antiparasite drug, modulator of the hostparasite relationship and immunosuppressant. Parasitology 105 (Suppl.), S25-S40.

Chiara, M.D., Bedoya, F. \& Sobrino, F. (1989). Cyclosporin A inhibits phorbol ester-induced activation of superoxide production in resident mouse peritoneal macrophages. Biochem. J. 264, 21-26.

Colombani, P.M. \& Hess, A.D. (1987) T-Lymphocyte inhibition by cyclosporine. Potential mechanism of action. Biochem. Pharmacol. 36, 3789-3793.

Conde, M., Andrade, J., Bedoya, F.J., Santa Maria, C. \& Sobrino, F. (1995) Inhibitory effect of cyclosporin A and FK506 on nitric oxide production by cultured macrophages. Evidence of a direct effect on nitric oxide synthase activity. Immunology 84, 476-481.

Dąbrowska, M., Zieliński, Z., Wranicz, M., Michalski, R., Pawełczak, K. \& Rode, W. (1996) Trichinella spiralis thymidylate synthase: Developmental pattern, isolation, molecular properties and inhibition by substrate and cofactor analogues. Biochem. Biophys. Res. Commun. 228, 440-445.

De Caterina, R., Tanaka, H., Nakagawa, T., Hauptman, P.J. \& Libby, P. (1995) The direct effect of injectable cyclosporine and its vehicle, cremophor, on endothelial vascular cell adhesion molecule- 1 expression. Ricinoleic acid inhibits coronary artery endothelial activation. Transplantation 60, 270-275.
Denis, M., Cormier, Y. \& Laviolette, M. (1992) Murine hypersensitivity pneumonitis: A study of cellular infiltrates and cytokine production and its modulation by cyclosporin A. Am. J. Respir. Cell Mol. Biol. 6, 68-74.

Despommier, D.D. (1993) Trichinella spiralis and the concept of niche. J. Parasitol. 79, 472482 .

Dick, A.D., Kreutzer, B., Laliotou, B. \& Forrester, J.V. (1997) Phenotypic analysis of retinal leukocyte infiltration during combined cyclosporin $\mathrm{A}$ and nasal antigen administration of retinal antigens: Delay and inhibition of macrophage and granulocyte infiltration. Ocul. Immunol. Inflamm. 5, 129-140.

Dzik, J.M., Gołos, B., Kapała, A., Wranicz, M. \& Wałajtys-Rode, E. (2000) Guinea pig lungs response to Trichinella spiralis infection. Acta Parasitol. 45, 192.

Egwang, T.G., Gauldie, J., \& Befus, D. (1984) Broncho-alveolar leucocyte response during primary and secondary Nippostrongylus brasiliensis infection in the rat. Parasite Immunol. 6, 191-201.

Elwood, W., Lotwall, J.O., Barnes, P.J. \& Chung K.F. (1992) Effect of dexamethasone and cyclosporin A on allergen-induced airway hyperresponsiveness and inflammatory cell responses in sensitized Brown-Norway rats. Am. Rev. Respir. Dis. 145, 1289-1294.

Forman, H.J., Zhou, H., Gozal, E. \& Torres, M. (1998) Modulation of the alveolar macrophage superoxide production by protein phosphorylation. Environ. Health Perspect. 106, (Suppl. 5) 1185-1190.

Gilliam, M.B., Sherman, M.P., Griscavage, J.M.Z. \& Ignarro, L.J. (1993) A spectrophotometric assay for nitrate using NADPH oxidation by Aspergillus nitrate reductase. Anal. Biochem. 212, 359-365.

Green, L.C., Wagner, D.A., Glogowski, J., Skipper, P.I., Wishnok, J.S. \& Tannenbaum, S.R. (1982) Analysis of nitrate, nitrite and [ $\left.{ }^{15} \mathrm{~N}\right] \mathrm{ni}$ trate in biological fluids Anal. Biochem. 126, $131-138$.

Hattori, Y. \& Nakanishi, N. (1995) Effect of cyclosporin A and FK506 on nitric oxide and 
tetrahydrobiopterin synthesis in bacterial lipopolysaccharide-treated J774 macrophages. Cell. Immunol. 165, 7-11.

Issekutz, T.B. (1989) Effects of anti-inflammatory agents on lymphocyte migration stimulated by the interferons, tumor necrosis factor and cutaneous inflammation. Int. J. Immunopharmacol. 11, 725-732.

Iyengar, R., Stuehr, D.J. \& Marletta, M.A. (1987) Macrophage synthesis of nitrite, nitrate, and N-nitrosoamines: Precursors and role of the respiratory burst. Proc. Natl. Acad. Sci. U.S.A. 84, 6369-6373.

James, S.L. (1995) Role of nitric oxide in parasitic infections. Microbiol. Rev. 59, 533-547.

Jesch, N.K., Dorger, M., Enders, G., Rieder, G., Vogelmeier, C.F., Messmer, K. \& Krombach, F. (1997) Expression of inducible nitric oxide synthase and formation of nitric oxide by alveolar macrophages: An interspecies comparison. Environ. Health Perspect. 105 (Suppl. 5), 1297-1300.

Kahan, B.D. (1994) Role of cyclosporine: present and future. Transplant. Proc. 26, 3082-3087.

Kunz, D., Walker, G., Eberhardt, W., Nitsch, D. \& Pfeilschifter, J. (1995) Interleukin 1- $\beta$-induced expression of nitric oxide synthase in rat renal mesangial cells is suppressed by cyclosporin A. Biochem. Biophys. Res. Commun. 216, 438-446.

Lagente, V., Carre, C., Kyriacopoulos, F., Boichot, E., Mencia-Huerta, J.M. \& Braquet, P. (1994) Inhibitory effect of cyclosporin A on eosinophil infiltration in the guinea-pig lung induced by antigen, platelet-activating factor and leukotriene B4. Eur. Respir. J. 7, 921-926.

Lindor, L.J., Wassom, D.L. \& Gleich, G.J. (1983) Effects of trichinellosis on levels of eosinophils, eosinophil major basic protein, creatine kinase and basophils in the guinea pig. Parasite Immunol. 5, 13-24.

Liu, J., Farmer, J.D., Lane, W.S., Friedman, J., Weissman, I. \& Schreiber, S.L. (1991) Calcineurin is a common target of cyclophilin, cyclosporin A and FKBK-FK506 complexes. Cell 66, 807-815.
Losa Garcia, J.E., Mateos Rodriguez, F., Jimenez Lopez, A., Garcia Salgado, M.J., Martin de Cabo, M.R., Perez Losada, J. \& Perez Arellano, J.L. (1998) Effect of cyclosporin A on inflammatory cytokine production by human alveolar macrophages. Respir. Med. 92 722-728.

Lu, D.J., Takai, A., Leto, T.L. \& Grinstein, S. (1992) Modulation of neutrophil activation by okadaic acid, a protein phosphatase inhibitor. Am. J. Physiol. 262 (Part 1) C39-C49.

Miller, H.R.P. (1984) The protective mucosal response against gastrointestinal nematodes in ruminants and laboratory animals. Vet. Immunol. Immunopathol. 6, 167-259.

Miller, R.A. \& Britigan, B.E. (1997) Role of oxidants in microbial pathophysiology. Clin. Microbiol. Rev. 10, 1-18.

Morel, F., Doussiere, J. \& Vignais, P.V. (1991) The superoxide-generating oxidase of phagocytic cells. Physiological, molecular and pathological aspects. Eur. J. Biochem. 201, 523-546.

Morris, S.M., Jr. \& Billiar, T.R. (1994) New insights into the regulation of inducible nitric oxide synthesis. Am. J. Physiol. 266 (Part 2), E829-E839.

Muramo, T., Nakaki, T., Hishikawa, K., Suzuki, H. Kato, R. \& Saruta, T. (1995) Cyclosporin A inhibits nitric oxide synthase induction in vascular smooth muscle cells. Hypertension 25, 764-768.

Nathan, C. \& Xie, Q.W. (1994) Regulation of biosynthesis of nitric oxide. J. Biol. Chem. 269, 13725-13728.

Navarro-Antolin, J., Rey-Campos, J. \& Lamas, S. (2000) Transcriptional induction of endothelial nitric oxide gene by cyclosporin A. A role for activator protein-1. J. Biol. Chem. 275, 3075-3080.

Nijkamp, F.P., van der Linde, H.J., Folkerts, G. (1993) Nitric oxide synthesis inhibitors induce airway hyperresponsiveness in guinea pig in vivo and in vitro. Role of the epithelium. Am. Rev. Respir. Dis. 148, 727-734.

Norris, A.A., Jackson, D.M. \& Eady, R.P. (1992) Protective effects of cyclophosphamide, cyclosporin A and FK506 against antigen-in- 
duced lung eosinophilia in guinea-pigs. Clin. Exp. Immunol. 89, 347-350.

Oswald, I.P., Wynn, T.A., Sher, A. \& James, S.L. (1994) NO as an effector molecule of parasite killing: Modulation of its synthesis by cytokines. Comp. Biochem. Physiol. Pharmacol. Toxicol. Endocrinol. 108, 11-18.

Prud'homme, G.P. \& Vanier, L.E. (1993) Cyclosporine, tolerance, and autoimmunity. Clin. Immunol. Immunopathol. 66, 185-192.

Rajagopalan-Levassieur, P., Lecointe, D., Bertrand, G., Fay, M. \& Gougerot, M.A. (1996) Differential nitric oxide (NO) production by macrophages from mice and guinea pigs infected with virulent and avirulent Legionella pneumophilia serogrup 1. Clin. Exp. Immunol. 104, 48-53.

Rochelle, L.G., Fischer, B.M. \& Adler, K.B. (1998) Concurrent production of reactive oxygen and nitrogen species by airway epithelial cells in vitro. Free Radicals Biol. Med. 24, 863-868.

Salter, M., Knowles, R.G. \& Moncada, S. (1991) Widespread tissue distribution, species and changes in activity of $\mathrm{Ca}^{2+}$-dependent and $\mathrm{Ca}^{2+}$-independent nitric oxide synthases. FEBS Lett. 291, 145-149.

Shirato, M., Sakamoto, T., Uchida, Y., Nomura, A., Ishii, Y., Iijima, H., Goto, Y. \& Hagesawa, S. (1998) Molecular cloning and characterization of $\mathrm{Ca}^{2+}$-dependent inducible nitric oxide synthase from guinea-pig lung. Biochem. J. 333, 795-799.

Siegel, S. (1956) Nonparametric Statistics for the Behavioral Sciences. Mc Graw-Hill Kogakusha Ltd., Tokyo.

Spector, T. (1978) Refinement of the Coomassie Blue method of protein quantitation. Anal. Biochem. 86, 142-146.

Suleymanlar, G., Suleymanlar, I., Shapiro, J.I. \& Chan, L. (1994) Possible role of lipid peroxidation in cyclosporine nephrotoxicity in rats. Transpl. Proc. 25, 2888-2889.

Svensson, U., Holst, E. \& Sundler, R. (1995) Cyclosporin-sensitive expression of cytokine mRNA in mouse macrophages responding to bacteria. Mol. Immunol. 32, 157-165.
Taskinen, H.S. \& Roytta, M. (2000) Cyclosporin A affects axons and macrophage during Wallerian degeneration. J. Neurotrauma. 17, 431-440.

Teixeira, M.M., Williams, T.J. \& Hellewell, P.G. (1996) Effects of dexamethasone and cyclosporin A on the accumulation of eosinophils in acute cutaneous inflammation in the guinea pigs. Br. J. Pharmacol. 118, 317-324.

Thomson, A.W. (1992) The effects of cyclosporin A on non-T cell components of the immune system. J. Autoimmun. 5 (Suppl A), 167-176.

Vodovotz, Y. (1997) Control of nitric oxide production by transforming growth factor- $\beta 1$ : Mechanistic insight and potential relevance to human disease. Nitric Oxide. 1, 3-17.

Vodovotz, Y., Letterio, J.J., Geiser, A.G., Chesler, L., Roberts, A.B. \& Sparrow, J. (1996) Control of nitric oxide production by endogenous TGF- $\beta 1$ and systemic nitric oxide in retinal pigment epithelial cells and peritoneal macrophages. J. Leukoc. Biol. 60, 261-270.

Wang, C.H. \& Bell, RG. (1986) Trichinella spiralis: Vascular recirculation and organ retention of newborn larvae in rats. Exp. Parasitol. 62, 430-441.

Wang, J.M., Denis, M., Fournier, M. \& Laviolette, M. (1993) Cyclosporin A increases the pulmonary eosinophilia induced by inhaled Aspergillus antigen in mice. Clin. Exp. Immunol. 93, 323-330.

Weatherly, N.F. (1983) Anatomical pathology; in Trichinella and Trichinellosis (Campbell, W.C., ed.) pp. 173-208, Plenum Press, New York, NY.

Weinberg, J.B., Misukonis, M.A., Shami, P.J., Mason, S.N., Sauls, D.L., Dittman, W.A., Wood, E,R., Smith, G,K., McDonald, B., Bachus, K.E., Haney, A.F. \& Granger, D.L. (1995) Human mononuclear phagocyte inducible nitric oxide synthase (iNOS): Analysis of iNOS mRNA, iNOS protein, biopterin, and nitric oxide production by blood monocytes and peritoneal macrophages. Blood 86, 1184-1195.

Wolf, A., Trendelenburg, C.-F., Diez-Fernandez, C., Prieto, P. \& Cordier, A. (1994) Role of gluta- 
thione in cyclosporine A in vitro hepatotoxicity. Transpl. Proc. 25, 2912-2914.

Xia, H. \& Bredt, S. (1998) Cloned and expressed nitric oxide synthase proteins. Methods Enzymol. 268 (Part A), 427-436.

Yamashita, T., Someya, A. \& Hara, E. (1985) Response of superoxide anion production by guinea-pig eosinophils to various soluble stimuli: Comparison to neutrophils. Arch. Biochem. Biophys. 241, 447-452.

Zhang, X. \& McMurray, D.N. (1998) Suppression of lymphoproliferation by alveolar macrophages in the guinea pig. Tuber. Lung Dis. 79, $119-126$. 